\title{
Amenazas al proceso de paz: La no-guerra y los nuevos señores de la guerra, una interpretación desde Baudrillard y Münkler
}

\section{Threats to the peace process: No-war and the new warlods, an interpretation from Baudrillard and Münkler}

\author{
John Jairo Pabón Erazo \\ Licenciado en Ciencias Sociales y Magister en Pedagogía \\ Magister en pedagogía Universidad Mariana \\ Email: jairopaboncs@gmail.com
}

Doi: https://doi.org/10.22267/rceilat.204647.90

\begin{abstract}
Resumen
El proceso de Paz en Colombia puso fin a uno de los enfrentamientos más largos del hemisferio occidental entre las F.A.R.C y el Estado colombiano. Sin embargo, éste se encuentra amenazado por diversos actores y circunstancias. Para comprender lo que es el proceso de paz es necesario hacer una conceptualización de la guerra en la primera etapa de la tercera posguerra, y para entender algunas de las amenazas por los que atraviesa el Acuerdo se hace necesario repensar el concepto de guerra a partir del mundo de finales del siglo XX e inicios del nuevo milenio. Los conceptos de no-guerra (Baudrillard) y nuevas guerras (Münkler) ayudan en la comprensión de las mayores amenazas que enfrenta el Acuerdo final para la terminación del conflicto en Colombia.
\end{abstract}

Palabras claves: No-guerra; Asimetría; Hiperrealidad; Nuevas guerras; Señores de la guerra

\begin{abstract}
The Peace process in Colombia ended one of the longest confrontations in the western hemisphere between the F.A.R.C and the Colombian State. However, it is threatened by various actors and circumstances. To understand what the peace process is, it is necessary to make a conceptualization of war in the first stage of the third post-war period, and to understand some of the threats that the Agreement is undergoing, it is necessary to rethink the concept of war from the world of the late twentieth century and the beginning of the new millennium. The con-
\end{abstract}


cepts of non-war (Baudrillard) and new wars (Münkler) help in understanding the greatest threats facing the final Agreement for ending the conflict in Colombia.

Keywords: Non-war; Asymmetry; Hyperreality; New wars; Warlords

El fin del mundo bipolar trajo consigo una gran cantidad de cambios para occidente en todos los niveles, aspectos y ámbitos de la vida política, social, económica y cultural. El fin del corto siglo XX (Hobsbawm 2007) traía consigo muchos cuestionamientos e incertidumbres. Precisamente, uno de los conceptos que empezó a revaluarse fue el de la Guerra. Finalizó, siguiendo el concepto de corto siglo, un período que se había iniciado en 1914, con la Gran Guerra y terminó en 1991 con la caída del socialismo real. El siglo que se había caracterizado por generar los conflictos armados-militares que involucran a todo el mundo llegaba a su fin. Sin embargo, ese fin no representaría el advenimiento de una paz o el fin de la guerra.

El concepto de guerra ha tenido un cambio dramático a finales del siglo XX y comienzos del nuevo milenio. La transformación se debió en gran parte a los cambios surgidos a partir del fin del enfrentamiento bipolar, el proceso de globalización y las nuevas formas de conflicto en el orden militar, político y de comunicación. Lo anterior queda demostrado a través de los postulados de autores como: Jean Baudrillard y Herfried Münkler. El primero, por medio de su teoría del hiperrealismo y la disuasión. Mientras que el segundo realizó un análisis de las nuevas guerras.
Existe un gran número de interpretaciones sobre el tema señalado, pero se escogen estos autores para un análisis por diversos motivos. En primer lugar, sus nacionalidades francés y alemán, es de conocimiento general la importancia de estos países en el mundo contemporáneo. Segundo, sus trabajos: la guerra del Golfo no ha tenido lugar (Baudrillard 1991) y Viejas y nuevas guerras: asimetría y privatización de la Violencia (Münkler 2005), la primera edición en alemán es del año 2002; son contemporáneos o cercanos al colapso de la Unión Soviética y el atentado del 11 de septiembre de 2001. Dentro de este marco se encuentra la Guerra del Golfo Pérsico y el inicio de la lucha contra el terrorismo internacional. Sin duda, es una espacialidad temporal interesante para una revisión de sus propuestas. En síntesis, se pretende realizar un análisis del concepto de guerra a partir de las lecturas de Jean Baudrillard y Herfried Münkler.

\section{El mundo de la tercera postguerra: In- tentos por entender el nuevo mundo}

Para comprender el concepto de guerra a finales del siglo XX y comienzo del nuevo milenio se han escogido las obras, ya mencionadas, de Baudrillard y Münkler. La selección se debe a unas características particulares de los autores, su formación 
y sobre todo, el mundo y el contexto en que sus textos fueron producidos. Las obras, una escrita por un filósofo y sociólogo francés; mientras que la otra, escrita por un profesor alemán de teoría política, abarcan una temporalidad de once años entre cada una. Sin embargo, el lapso del tiempo tiene una importancia fundamental, no solo para sus trabajos sino para todo el mundo contemporáneo occidental. Por lo anterior, se hace necesario revisar el contexto de escritura para comprender la posición de los autores con respecto a la guerra.

La guerra del Golfo no ha tenido lugar es una compilación de tres artículos que Jean Baudrillard escribió en 1991, entre los meses de enero a marzo, para el periódico parisino $L i-$ bération. Por su parte, Viejas y nuevas guerras: Asimetría y privatización de la violencia, de Münkler, es un ensayo publicado por primera vez en alemán en el año 2002. Los años de aparición de estos trabajos son de una importancia mayúscula, se encuentran cercanos al periodo comprendido entre el final de la Guerra fría, con el colapso de la Unión Soviética, y los atentados al World Trade Center. Cada uno de estos acontecimientos traerá cuestionamientos y nuevas interpretaciones sobre el conflicto, la violencia y la guerra.

El año de 1991 marcará, según la propuesta desarrollada por de Eric Hobsbawm, el fin del corto siglo XX. Un siglo que se caracterizó por una serie de acontecimientos y desarrollos en los cuales la guerra desempeñaría un papel estelar. Este periodo que pa- radójicamente inició con una guerra caliente, termina con una guerra fría. El fin de la bipolaridad o conflicto Oeste-Este marcó el inicio de una nueva era, pero ¿qué significó esa ruptura en el plano de la guerra?

El conflicto entre capitalismo, representado por los Estados Unidos y socialismo por la Unión Soviética, llegaba a su fin a inicios de los años noventa. Fue la culminación del enfrentamiento que con mayor intensidad puso bajo amenaza la existencia humana, la Guerra Fría. Un gran número de acontecimientos y procesos, tanto en el Oeste como en el Este, llevaron a este acontecimiento mundial. Las manifestaciones de esperanza y las expectativas sobre el devenir del mundo no se hicieron esperar, especialmente con respecto a la interpretación de la guerra.

La primera tesis que causó impacto en su momento sobre el devenir de la humanidad fue El fin de la historia $y$ el último hombre de Francis Fukuyama (Fukuyama 2000). En este trabajo, un tanto audaz, se plantea el fin de los conflictos por motivos ideológicos, llegando a un estado en el cual se daría fin a las guerras. Lo anterior, es defendido a partir de una postura hegeliana; para Fukuyama “...La historia es el despliegue de un gran principio mediante conflictos y movimientos pendulares, tesis y antítesis. Una vez que estos antagonismos se resuelvan en una última síntesis (global), reinará en todas partes la vida "normal" y no habrá ya una historia relevante que contar" (Dahrendorf 2001, 233). La 
vida "normal" a que se hace alusión podría ser un estado de paz. Sin embargo, la postura de este autor norteamericano con raíces japonesas, pronto se pondría en cuestión y fue refutado no sólo teóricamente sino en el espacio de la realidad y los conflictos que surgieron luego.

Por los años noventa, y superada la teoría del fin de la historia, otro autor dará a conocer al mundo sus posturas sobre lo que se avecina y con respecto a la guerra. Igualmente criticado, El choque de civilizaciones de Huntington (Huntington 1997) es una propuesta que no habla sobre el fin de los conflictos y las guerras sino de un cambio. Para Fukuyama el principal generador de conflictos era la lucha por el reconocimiento y la ideología, con su terminación del conflicto se llega a lo "normal". En cambio, Huntington plantea que los conflictos ya no serán de tipo ideológicos después de la caída del muro, sino que se presentará un choque entre las ocho civilizaciones, que él reconoce: japonesa, china, musulmana, hindú, ortodoxa, occidental, latinoamericana y africana. "En adelante diagnóstica Huntington, los que se enfrentan ya no son bloques ideológicos y políticos sino estilos culturales, grupos de países que pertenecen a la misma civilización" (Todorov 2008, 131) Para este autor se presenta una clara defensa de la cultura Occidental, la cual se encuentra en una amenaza latente.

Los anteriores textos son visiones diferentes sobre el mundo que se vivía y su preocupación por el vacío que dejó la Guerra Fría. Coinciden en ser unas de las tantas y nuevas interpretaciones que se le dará a la guerra. Puede acompañarlos una compilación de textos de Ralf Dahrendorf, quien postula que a partir de la de la Revolución de 1989 o caída de la Nomenklatura se presenta un recomienzo de la historia. Es decir, "La historia, encerrada tanto tiempo en la coexistencia estéril de sistemas que se necesitaban mutuamente para impedir el cambio o para mantenerlo bajo control, volvió a ponerse en marcha" (Dahrendorf 2001, 242). Ahora, siguiendo a Dahrendorf, se presenta una defensa de los valores occidentales.

Atrás quedaba las interpretaciones del mundo bipolar abriendo paso a nuevas propuestas. Es decir, los conflictos presentados a partir de 1991 ya no se pueden entender con las lógicas del periodo de la Guerra Fría. Tampoco se puede hablar de su fin, es más, la realidad muestra cómo estos se extendieron sobre todo en los márgenes y contornos de los países desarrollados.

\section{La guerra del Golfo no ha tenido luga. Una interpretación desde lo virtual}

Casi en paralelo con la disolución de la Unión Soviética y junto con el ocaso de la confrontación Oeste-Este un nuevo conflicto se presentaba en Oriente Medio, la Guerra del Golfo. Esta conflagración se puede considerar como la primera confrontación armada de la tercera postguerra. Es decir, las nuevas interpretaciones comienzan a salir a luz. Una de esas pri- 
meras explicaciones ante el conflicto en mención la brindará Jean Baudrillard con su texto: La guerra del golfo no ha tenido lugar.

El texto la Guerra del Golfo no ha tenido lugar fue escrito durante el proceso de confrontación entre la Fuerza de Coalición de las Naciones Unidas, a la cabeza de Estados Unidos, e Irak. En realidad, el texto es la compilación de tres artículos que aparecieron a principios del año 1991 en el periódico parisino Libération. Es decir, son tres escritos separados en tiempo que iban construyendo el autor a través de lo que presenciaba y pensaba sobre la guerra que acontecía en Oriente medio: La guerra del Golfo no tendrá lugar, ¿está teniendo lugar la guerra del Golfo? y la guerra del Golfo no ha tenido lugar. Los títulos de los artículos dan una idea sobre a qué etapa de la guerra se refería. Por otro lado, tiene una importancia comprender la intención del autor al escribir para un periódico con una fundación, recorrido y público reconocido como es la intelectualidad y militantes de línea centro izquierda. Es de señalar que el Libération para estos años pasaba por un momento de transición en su postura político-ideológica desplazándose hacia una línea socialdemócrata. A pesar de los dilemas que se presentaban en el diario parisino no se puede negar su sensibilidad hacia la realidad social y política, características desde su creación en 1973.

Baudrillard hizo un cubrimiento de la guerra del Golfo a partir de su teoría de la hiperrealidad y la simula- ción. Si bien, la formación del autor es de filósofo y sociólogo, no de militar, y por otro lado, no estuvo presente en el lugar de las acciones bélicas, brindó una interpretación interesante a la luz de las nuevas formas de comunicación y de hacer la guerra. A Baudrillard se le ofreció cubrir los acontecimientos que ocurrían en Irak, su respuesta nos adentra en su postura teórica: "Vivo en lo virtual. Si me enviaran a lo real no sabría qué hacer" (Horrocks y Zoran 2006, 120). Su postura es interesante y se ajusta a su hipótesis sobre la hiperrealidad. “...es que los simulacros, las estrategias de simulación determinan la actual condición del mundo social y político. Nada es real sin una escena hiperreal similar al mundo del espectáculo” (Verdú 1991) Esta manera de ver la realidad hará que se revalúe la posición de Clausewitz sobre "la guerra como la política por otros medios"; para hablar de la no-guerra, "la ausencia de política que sigue por otros medios".

Baudrillard comienza sus artículos haciendo alusión al hecho que de antemano se sabía que la guerra no se iba producir. Quizá para un lector poco familiarizado con los temas de la guerra y el no-acontecimiento esta afirmación puede ser polémica. Se diría que las imágenes y el armamento estuvieron ahí, en la guerra; hubo transmisión en vivo y directo de los hechos que ocurrían, se observaron los bombardeos, entonces ¿Cómo comprenden el concepto de no-guerra?

Siguiendo la línea argumental del autor se puede rescatar el concepto 
de guerra muerta, es decir la descongelación de la guerra Fría. La cual no se parece a sus predecesoras: la guerra caliente (violencia del conflicto) y la guerra fría (equilibrio del terror). Ya no se producirá una guerra por la correlación de fuerzas. se presenta según sus palabras el no-acontecimiento, la no-guerra.

Para comprender mejor la postura de la no-guerra hay que acudir a los presupuestos teóricos y conceptuales a los que se refiere el autor. El término en mención se relaciona con su propuesta de hiperrealidad y el simulacro. Es decir, cuando se acude a ellos se habla de algo que no tiene origen en la realidad, es más real que lo real. En otras palabras, puede ser: "Una realidad virtual que, en gran medida no es sino creación de realidad o hiperrealidad” (Vásquez Rocca 2015, 152). Para el caso de la guerra del Golfo lo anterior es una advertencia para los espectadores desprevenidos, aquellos que viven en la desinformación y no tienen las posibilidades de establecer una crítica. Por otra parte, el simulacro se entiende como la proliferación de demasiada realidad, llevando al fin de la misma "Lo real está desapareciendo, no es debido a la su ausencia; sino, precisamente porque hay demasiada realidad. Y en este exceso de realidad lo que pone fin a la realidad" (Vásquez Rocca 2015, 153). En conclusión, tenemos una realidad virtual, creada y de la cual se nos satura, y un claro ejemplo de ello es la guerra del Golfo.

Para Baudrillard, apoyándose en sus presupuestos, la no-guerra es: "Pu- blicitaria, especulativa, virtual; de hecho, esta guerra ya no responde a la forma de Clausewitz de la prolongación de la política por otros medios; resulta más bien de la carencia de política prolongada por otros medios” (Baudrillard 1991, 21). Es precisamente esa ausencia de política la que hace que no exista. Los bombardeos, las muertes o enfrentamientos existen, pero no una guerra. En la guerra del Golfo lo que se encuentra es manipulación, la disuasión a partir del chantaje, en el cual las personas son rehenes de la información y los medios; obligadas a creer por una saturación de imágenes.

La guerra pasa a ser una simulación ya que se pierde la función simbólica, deja a un lado al enemigo el cual no merece ser desafiado. Volviendo a Clausewitz, éste menciona como la guerra debe conocer su fin y buscar triunfar para ese logro, se reconoce a un adversario y se habla de una batalla decisiva (Clausewitz 1983). Con la no-guerra se observa la desaparición del paso simbólico, no existe una declaración por lo tanto nunca arrancó, llevando a una guerra que nunca terminará. Con esto la realidad aparece como una simulación en donde existe un ganador de antemano. Se está ante una nueva manera de confrontación quirúrgicamente diseñada para que exista un ganador.

La no-guerra es la escenificación a partir de los medios de comunicación de una realidad. Es la proliferación de demasiada realidad, en donde la política está ausente. Se caracteriza por ser especulativa y de alta rentabilidad. 
En otras palabras, se convierte en un producto para la demanda, hablando en términos psicoanalíticos. Para finalizar, el autor menciona cómo la guerra del Golfo sirvió para mantener el nuevo orden mundial, en los lugares deseados no hubo nada; las cosas están dentro del orden democrático, se ha terminado el desorden que para el caso de la época fue el fin del comunismo. En conclusión, la nueva guerra después del fin del conflicto Oeste-Este nos pone a cuestionar no solo lo militar sino la existencia a partir de la hiperrealidad.

\section{Las viejas y nuevas guerras: interpre- taciones ante los nuevos desafíos}

Haciendo una ruptura temporal se pasa a analizar otro texto que sale a la luz después del atentado del 11 de septiembre de 2001. Los aportes que brinda consolida la propuesta de nuevas guerras planteadas por Mary Kaldor y hace una reinterpretación a un clásico, Clausewitz; además ofrece una mirada panorámica para comprender los nuevos conflictos. Si la propuesta de Baudrillard se centraba en lo virtual, Las viejas y nuevas guerras de Herfried Münkler tocarán el plano de lo real en la confrontación. Por consiguiente, será lo material, su transformación y los objetivos de las nuevas guerras sus intereses. El contexto de las nuevas guerras es también otro punto fundamental, y la lucha contra el "terrorismo internacional" marcará una nueva ruta.

En el año 2002, en Alemania, se publicó un ensayo titulado Die neuen kriege el cual fue un éxito en ventas. El libro tuvo tal acogida que para el año 2005 ya circulaba su traducción al español, y en varias lenguas, bajo el título: Viejas y nuevas guerras: asimetría y privatización de la violencia (Münkler 2005). En este trabajo Münkler, quien es profesor y analista político, hace un diagnóstico del mundo contemporáneo, realiza una teorización sobre la guerra y de cierta manera reinterpreta a un clásico como lo fue Clausewitz, aclarando que esta nueva visión la hace sobre todo por las circunstancias de la época en la que escribía. Sus argumentos basados en lo político militar tendrán un soporte en la propuesta de las nuevas guerras de Mary Kaldor. El trabajo se centra en argumentar cómo las nuevas guerras se han transformado, no se las puede entender bajo la premisa de las guerras formadoras de Estados. Por otra parte, existen nuevos señores de la guerra que aprovechando las ventajas de la asimetría de los nuevos conflictos hacen que estos sean de difícil resolución y pueden convertirse en una forma de lucro, en una economía y mercantilización de la guerra.

Münkler en la introducción de su ensayo inicia haciendo alusión al desuso en que se encuentran las clásicas guerras entre estados. Menciona como estas han perdido su fin político para pasar a fines económicos, páginas adelante parafraseando a Clausewitz dirá: “(...) Afirmamos por el contrario que la guerra no es más que una prosecución del comercio político con la intervención de otros medios" (Münkler 
2005, 44). Lo anterior no quiere decir que se hayan perdido las motivaciones ideológicas, étnicas, culturales o religiosas; ahora, lo lucrativo tiene una prioridad sobre lo demás. Tomando como base la propuesta de Mary Kaldor sobre las nuevas guerras (Kaldor 2001) establecerá unas características propias para la confrontación. Por consiguiente, se resaltan cambios en la financiación y las formas de luchar pasando a otra etapa de la guerra; que bien podría ser un retroceso, por sus características, a las formas de enfrentamiento ocurridas en la Guerra de los Treinta Años.

Para adentrarse en el tema, caracterizó, las viejas guerras como fenómenos europeos de los siglos $\mathrm{XV}$ y XIII, ligadas a la formación de Estados, y se podría decir llegaron hasta la culminación del conflicto bipolar entre las dos superpotencias (E.E.UU y U.R.S.S) del siglo XX. De alguna manera se explican bajo la lógica del Karl Von Clausewitz: hay un pensamiento militar, se considera una actividad social y puede enmarcarse dentro de un instrumento político (Forigua Rojas 2006). Las guerras del siglo XX, en su mayoría, se pueden asociar a estas particularidades. Sin embargo, las luchas revolucionarias, las low intensity war y las limpiezas étnicas, no sólo modifican la forma de lucha, sino que también generan una nueva forma de comprender el fenómeno de la guerra.

Las nuevas guerras se caracterizan por varios factores que les dan un tinte diferente a los procesos bé- licos que se conocían entre Estados, las nuevas particularidades llevan a hablar de guerras intrasociales: en primer lugar, Son confrontaciones de larga duración, no existe un comienzo o final claro. Lo anterior, se debe principalmente al hecho de que los nuevos grupos de combatientes han tomado como estrategia la asimetrización, es decir, al no tener la posibilidad de hacer una lucha de disuasión a través de la demostración de poder, se plantea la necesidad de establecer mecanismos para establecer una estrategia defensiva. Por lo tanto, no hay un enfrentamiento directo, sino que se puede presentar en cualquier momento y mantenerse latente por un largo periodo de tiempo, las guerras de guerrillas es un ejemplo. Ya no se pretende doblegar la voluntad del adversario, hablando en términos clásicos. Al no existir una legitimidad política se pueden mantener por mucho tiempo en una larga guerra de aguante. Es de resaltar que estos fenómenos se presentan en la periferia de los países potencias, pero que de alguna manera empiezan a sentir en sus territorios los efectos.

En segundo lugar, son guerras intrasociales, el enfrentamiento no se presenta entre Estados sino entre grupos y Estado. Los mecanismos de la guerra tal como lo establece Clausewitz no se presentan para este caso: no existe una concentración de grupos, estos se encuentran dispersos, no hay disciplina militar. Los más afectados no son los combatientes sino la población civil; el miedo es un factor determinante, en donde las formas 
aberrantes y degeneradas de la confrontación hacen presencia: tortura, masacres, reclutamiento forzado, el uso de niños como combatientes, la violencia de género y agresión sexual entre otras modalidades empleadas para generar terror en la población. Por estas características no se puede hablar ya de tratados de paz sino de acuerdos. Las nuevas guerras pueden generar un desgaste de años por eso se hace necesario que las partes involucradas se sienten a negociar y a establecer patrones de mucho beneficio tanto en lo político, militar, social y económico; brindando garantías de reintegración para quienes se encuentren en la disposición de dejar la lucha armada.

En tercer lugar, la guerra se ha transformado en una modalidad de ascenso social y en una "actividad económica”. Para Münkler, teniendo en cuenta el mundo para el que escribe, la guerra es barata; este abaratamiento se debe a varios factores: el reclutamiento forzado de menores, limitando el uso de profesionales del combate; el desarrollo de armamento ligero, armas fáciles de manejar, ocultar y llevar; las ayudas internacionales, las cuales por lo general son manejadas por los combatientes y llegan muy poco a la población civil, que por lo general se convierten en abastecimiento; el desarrollo de medios de información, posibilitando la publicidad y proyección de las luchas. Lo anterior, sumado a otros factores de tipo material han hecho que una nueva clase emerja: los señores de la guerra, personajes que se lucran y han hecho un modus vivendi de los conflictos y la violencia, llevando a una privatización y mercantilización de la guerra. Volviendo a Clausewitz se podría parafrasear en esta ocasión su sentencia famosa de la siguiente manera: "Afirmamos por el contrario que la guerra no es más que una prosecución del comercio político con la intervención de otros medios" (Münkler, 2005, 44). Por consiguiente, se puede concluir que la guerra entre estados dejó de ser rentable, mientras que las nuevas guerras privatizan las ganancias y hacen colectivas las pérdidas.

Para finalizar, las nuevas guerras son un fenómeno que presentan unas características que hacen que las interpretaciones sobre la guerra se transformen. Las nuevas formas de confrontación están llevando a un atavismo en la confrontación, ya que se presentan semejanzas con las guerras anteriores al siglo XVII. La simetría que consistía en la forma de disuasión de los estados a partir de medir fuerzas ha quedado revaluada, generan una estrategia de asimetrización, es decir, buscar las formas de combatir contra quien por capacidad, es más poderoso. Y, la privatización de la violencia; lo que anteriormente se consideraba un monopolio del Estado ahora está siendo manejado por unos señores de la guerra que han hecho de ella una nueva forma de comercialización y mercantilización. Con todo lo anterior, se puede decir que la manera de conceptualizar y teorizar la guerra ha dado un giro que lleva buscar nuevas maneras de comprender el fenómeno. 
La no-guerra y los señores de la guerra como amenaza para el proceso de paz en Colombia

Después de realizar un acercamiento a las propuestas planteadas por Baudrillard y su concepto de no-guerra; como de Münkler sobre la teorización de las nuevas guerras, es necesario revisar como estas contribuyen en la comprensión de este fenómeno en Colombia. La idea no consiste en realizar una explicación a profundidad sobre el conflicto armado, lo cual tomaría mucho espacio y generaría discusiones que aún en los medios académicos y políticos se encuentran a la orden del día. Dentro de este texto se pretende esbozar un acercamiento que de alguna manera explica dos amenazas que puede tener la implantación del proceso de paz en Colombia.

Los planteamientos de Baudrillard y Münkler se ubicaron en una temporalidad para hacer un acercamiento a sus posturas. En el primer caso se toma como referente el fin del corto siglo XX. Y para el caso de las nuevas guerras el referente se centró en los acontecimientos del 11 de septiembre y los inicios de la lucha contra el terrorismo. Los trabajos realizados en otros contextos sirven para realizar aproximaciones y generar propuestas. Si bien es cierto que Colombia se enmarca dentro de los procesos del mundo occidental, no se puede decir que estos sean una réplica en el contexto local. Por consiguiente, desde la perspectiva de este texto la firma del acuerdo de Paz entre las FARC y el Estado significó el fin del siglo XX colombiano, el cual había iniciado, hablando en términos históricos, a finales de la década de los veinte y principios de los treinta; concretamente con la vinculación del país al proceso de modernización y modernidad. concluyendo con el acuerdo final para la terminación del conflicto y la construcción de una paz estable y duradera. Con el cual se da fin a uno de los fenómenos políticos surgido en los tiempos de la guerra fría, que se mantuvo vigente a pesar de la caída del socialismo real y la lucha antiterrorista.

El conflicto armado en Colombia tiene unos orígenes que fueron cambiando con el tiempo, pero con unos problemas socio-económicos transversales que están presentes desde la colonia hasta la actualidad: el problema de la tierra, la participación política, la inequidad y la desigualdad social. El conflicto que dio origen a las guerrillas surge a mediados del siglo XX cronológico, teniendo una motivación social a raíz de la exclusión del campesinado. Sumando a esto se tiene un fuerte sistema bipartidista que no permitió que otra opción democrática se hiciera posible. Por consiguiente, se puede hablar de un origen político con propósito social. Sin embargo, el conflicto no solo ha dependido de factores internos también están los externos que de una manera importante han contribuido a su consolidación y su transformación. Dentro del contexto internacional se puede mencionar que el conflicto es coetáneo con la Revolución Cubana y la Guerra Fría, las cuales harán sus aportes en la forma- 
ción de las guerrillas revolucionarias por una parte y su contraofensiva por otra.

De un origen socio político el conflicto armado fue transformándose hasta llegar a hablar de una "guerra". Pero estaríamos ante una guerra de baja intensidad, en donde la simetría solo se basa en lo político. Los grupos armados en las décadas de confrontación crecieron de manera considerable. Sumado a lo anterior, nuevos actores se fueron agregando y la guerra se convirtió en un elemento de ascenso social y en un negocio lucrativo. Las formas de financiación que encuentran los grupos involucrados hacen que lo militar vaya a primar sobre lo político. Este último punto llevó a que la lucha entre las fuerzas que inicialmente buscaron participación política a través de la vía armada, entrase en un conflicto que se puede mantener por muchas décadas debido a la transformación económica. La opción posible es la terminación del conflicto en búsqueda de participación política o el mantenimiento de una confrontación por décadas, bajo los presupuestos de las nuevas guerras. La firma del acuerdo de paz se logró porque las partes involucradas en el conflicto se dieron cuenta de que a corto plazo no habría un ganador. Existían dos fuerzas que no podían vencer. Por ello, era necesario hacer un reconocimiento al adversario y generar un proceso de negociación, el cual se firmó en el año 2016.

Pero este acuerdo desde sus etapas exploratorias tuvo enemigos, personas, colectividades políticas, grupos empresariales y actores armados que no estaban dispuestos a un cambio y a la búsqueda de la paz. Los motivos para estar en contra son mucho; van desde lo político, lo económico, los intereses particulares, el miedo a la verdad, entre otros. Por ello, con las nuevas formas de la guerra se habla de unas amenazas al proceso de paz. Tomando en cuenta a los autores señalados-Baudrillard y Münkler- estas no son ajenas a nuestro contexto.

Una de las primeras amenazas es precisamente el hecho de la no-guerra. El sentido de lo político se ha perdido, existe la no política dentro del conflicto. Los fines y propósitos de los actores involucrados ya no responde a un propósito de participación democrática. Sumando a lo anterior, se puede decir que la sociedad colombiana se encuentra secuestrada en una hiperrealidad en donde los medios de información han desempeñado un papel devastador:

"En el ámbito político-ideológico es necesario destacar el papel cumplido por los medios de comunicación vinculados a los centros de poder hegemónicos. En el desarrollo de este prolongado conflicto han asumido, de manera cada vez más extendida, la función de instrumentos de propaganda de la guerra contrainsurgente, aplicando técnicas de comunicación crecientemente sofisticadas. Sus espacios de acción comprenden desde la legitimación del orden dominante y la deslegitimación de cualquier expresión disiente que implique crítica al mismo hasta la sutil justificación y 
el encubrimiento de las formas ilegales de apoyo de este orden como es el caso de las organizaciones paramilitares" (Molano, 2015) La anterior cita nos ubica en el problema de la hiperrealidad y el no-acontecimiento. No quiere decir que la confrontación no existe, pero se satura al público de una información que muchas veces no es real, y es ayudada por imágenes en un mundo virtual. Con esa tergiversación de lo real quedamos aterrorizados ante una guerra que no está ahí.

Por otro lado, la guerra se ha convertido en un negocio y existe una forma de comercialización y de lucro a partir de ella, no solo de un enriquecimiento material sino también de un caudal político. Es aquí en donde las lógicas de las nuevas guerras dan paso ya no a actores armados políticos sino, a, señores de la guerra. Personajes siniestros que sacan provecho de mantener un conflicto así éste ya no tenga un fin socio-político. El mantener la guerra da beneficios, además las formas de asimetrización hacen que sea un negocio rentable, porque como se menciona más arriba las ganancias se concentran mientras que las pérdidas se comparten. En consecuencia, la paz que es un proceso a largo plazo se ve amenazada por estos grupos y personas quienes aparentan intención de negociación pero que a la larga por las condiciones que proponen, lo, único que expresan es su intención de mantener la guerra. Ya no se habla de un conflicto social armado sino de un negocio, la guerra.

\section{Conclusiones}

El fin del siglo XX trajo consigo muchos cambios en diversos aspectos de la vida y el acontecer de Occidente. Quizá la ruptura más grande que presenció la humanidad fue la caída del socialismo real y el ascenso hegemónico de la democracia liberal y la economía de mercado; atrás quedaba la confrontación entre el Este y el Oeste por imponerse entre sí. Debido a que la lucha entre estos sistemas se hizo a partir de la disuasión y la carrera armamentista en la Guerra Fría, su fin significó no sólo un triunfo sino la necesidad de reconsiderar y repensar la historia y su devenir, en donde la guerra se encontrará en una posición de cuestión y privilegio, la pregunta parecía ser ¿Qué viene ahora?

El fin de la polaridad llevó a nuevas interpretaciones especialmente para los temas de la guerra, el conflicto y la violencia. En la década de los noventa surgieron propuestas para tratar de comprender el nuevo orden global. Algunas de las teorías que salieron a la luz fueron cuestionadas y paradójicamente de mucha difusión, el fin de la historia y el choque de civilizaciones, las cuales trataron de buscar nuevos conflictos y maneras de comprender el devenir y el temor de Occidente. Sin embargo, el mundo iba mostrando otra faceta sobre la guerra, el conflicto y la violencia.

Después de la caída del muro de Berlín en 1989 otro acontecimiento que paralizó al mundo y marcó un nuevo rumbo en Occidente fue el aten- 
tado del 11 de septiembre de 2001. En medio de ese lapso de tiempo se produjeron nuevos conflictos y se mantuvieron otros, parecía que la premisa del fin de la historia solo era una ilusión. Los conflictos, las guerras y diversos tipos de violencia se presenciaban de manera permanente en un mundo globalizado e interconectado. Dentro de estos procesos hubo diferentes autores que trataron de interpretar qué ocurría en el mundo y vieron la necesidad de repensar el concepto de guerra.

Entre las múltiples interpretaciones sobre la guerra hay dos que llamaron la atención por su originalidad e innovación: las de Baudrillard y Münkler. Ambos autores hacen una revisión a uno de los clásicos como lo fue Karl Von Clausewitz a partir del contexto en que escribían sus obras. Baudrillard cubrió, en la virtualidad, la primera guerra después de terminado el conflicto Oeste-Este, la guerra del Golfo; a la cual a través de su teoría de la hiperrealidad y la simulación le dio una explicación. Concluyendo que la guerra no tuvo lugar, porque la guerra como continuación de la política por otros medios había sido relegada por la no-política por otros medios. Por otro lado, Münkler poco más de una década después, analizando los fenómenos de guerra y conflictos de la tercera postguerra, verá que las dinámicas han cambiado y se soportará en el concepto de nuevas guerras para argumentar que ya no es lo político lo que motiva las confrontaciones y a los combatientes. Ahora, existen nuevos intereses y modalidades de confrontación que como resultado han genera- do el paso a las guerras intrasociales $\mathrm{y}$ al ascenso de los nuevos señores de la guerra. La política ya no será un eje central, para este autor la guerra es una prosecución del comercio político por otros medios.

Las propuestas presentadas no son las únicas existentes ni las más reconocidas, pero de alguna manera aportan en la comprensión del fenómeno de la guerra. Los contextos en los que se escribieron los libros y la formación de sus autores hacen que sea difícil encontrar coincidencias; más sus aportes fueron valiosos para conocer sobre el tema desde perspectivas diferentes. El mundo del nuevo milenio tiene problemas heredados como nuevos desafíos, $\mathrm{y}$ es precisamente el conocer diversos puntos de vista una de las maneras para tratar de comprender y tomar posiciones ante los acontecimientos de guerra en el Nuevo Orden Mundial.

En el caso del proceso de paz llevado a cabo entre las FARC y el Estado Colombiano se ve cómo los elementos estructurales que dieron origen al conflicto armado han ido mutando a través del siglo XX. Esto ha hecho que las propuestas de los autores señalados, Baudrillar y Münkler, sean aplicables como amenazas que deben afrontar no solo el proceso de paz sino la sociedad en general. El panorama no es para nada alentador, si bien se abrió paso a la opción de la negociación y la paz, hay que tener en cuenta que este es un proceso de largo aliento, el cual tiene que navegar contra la corriente de la no-guerra y los señores de la guerra. 


\section{Referencias}

Baudrillard, J. (1991). la guerra del Golfo no ha tenido lugar. Barcelona, España: Anagrama.

Clausewitz, K. V. (1983). De la guerra. Buenos Aires, Argentina: Ediciones del Solar.

Dahrendorf, R. (2001). El recomienzo de la historia: de la caída del muro a la guerra de Irak. Buenos Aires, Argentina: Katz.

Forigua Rojas, E. (2006). «Las nuevas guerras: un enfoque desde las estructuras organizacionales.» Pap Politi, 11(1), 305-352.

Fukuyama, F. (2000). El fin de la historia y el último hombre. Santa Fé de Bogotá, Colombia: Planeta.

Hobsbawm, E. (2007). Historia del siglo XX: 1914-1991. Barcelona, España: Crítica.

Horrocks, C., y Jevitc, Z. (2006). Jean Baudrillard para principiantes. Buenos Aires, Argentina: Naciente SRL.

Huntington, S. (1997). El choque de las civilizaciones y la reconfiguración de orden mundial. Barcelona, España: Paidós.

Kaldor, M. (2001). Las nuevas guerras: violencia organizada en la era global. Barcelona, España: Tusquets.

Molano, A. (2015). Fragmentos de la historai del conflicto armado 1920-2010. En C. H. Colombia, Contribución al entendimiento del conflcto armado en Colombia (pág. 809).

Münkler, H. (2005). Viejas y nuevas guerra: asimetría y privatización de la violencia. Madrid, España: Siglo XXI.

Todorov, T. (2008). El miedo a los bárbaros: más allá del choque de civilizaciones. Barcelona, España: Galaxia Gutenberg.

Vásquez Rocca, R. (2015). Baudrillard y Danton: simulacros y políticas del signo después del fin del arte. AdVersuS, 148-164.

Verdú, V. (1991). La guerra del Golfo no ha existido. El país. 